


\title{
Sex differences in the serum level of endogenous ligands for estrogen receptor $\beta$ in the elderly population
}

Received: 24 February 2016

Accepted: 25 April 2016

Published: 11 May 2016
Miyuki Kobayashi ${ }^{1,2}$, Nobuhiro Sugiyama ${ }^{1}$, Daimei Sasayama ${ }^{1}$, Hidehiko Sasamoto ${ }^{3}$, Yoshimichi Miyashiro ${ }^{3}$, Kunimasa Arima ${ }^{2} \&$ Shinsuke Washizuka ${ }^{1}$

Animal studies suggest that estrogen receptor $\beta$ (ER $\beta)$-agonists, but not $E R \alpha$-agonists, are antidepressants. Several endogenous ligands for ER $\beta$ have been proposed, including $5 \alpha$-androstane-3 $\beta$, $17 \beta$-diol (3/Adiol), Androstenediol ( $\Delta 5$-diol), and $7 \alpha$-hydroxydehydroepiandrosterone ( $7 \alpha-\mathrm{OH}$-DHEA). The aim of this study was to determine the serum and salivary levels of natural ER $\beta$ ligands in men and women with and without past depressive episodes in the elderly population. DHEA (a precursor of 33Adiol, $\Delta 5$-diol, and $7 \alpha$-OH-DHEA), 17 $\beta$-estradiol (E2), and cortisol (F) were also measured. Samples were collected from 51 subjects and liquid chromatography tandem mass spectrometry was used for measurement. Comparisons were made between groups based on sex and depression history. E2, $3 \beta A d i o l$, and $\Delta 5$-diol levels were significantly lower in women than in men regardless of depression history. There were no significant differences between men and women in DHEA or $7 \alpha-\mathrm{OH}-\mathrm{DHEA}$ levels. DHEA was significantly lower in women with depression than in women without depression. Reduced DHEA levels may be related to depression vulnerability in women. Further studies are needed to determine the mechanism underlying sex differences in the prevalence of depression and increased risk of depression during menopause. Not only E2 but also two other estrogenic steroids (3ßAdiol and $\Delta 5$-diol) should be involved in these studies.

Our previous animal experiment has shown the following: [1] Estrogen receptor $\beta(E R \beta)$, not estrogen receptor $\alpha(E R \alpha)$, is abundantly expressed in the lateral part of the dorsal raphe (DR); [2] ovariectomy (OVX) leads to the loss of ER $\beta$ and loss of tryptophan hydroxylase- (TPH-) immunoreactivity in this area of the midbrain; and [3] TPH levels can be restored by the administration of 173-estradiol (E2) and, more strongly, by an ER $\beta$-selective ligand (LY3201) within a critical temporal window after OVX ${ }^{1}$. Similarly, Donner et al. have shown that administration of another ER $\beta$-selective ligand (diarylproprionitrile) increases Tph2 mRNA expression in female rat brain after OVX and that it decreases their depression-like behavior in the forced swim test paradigm ${ }^{2}$. These results suggest that ER $\beta$ mediates estrogen regulation of TPH levels and that ER $\beta$ ligands may be useful for the prevention of postmenopausal depression if administered shortly after menopause. However, it is still unknown which endogenous ER $\beta$ ligands are related to the pathophysiology of depression.

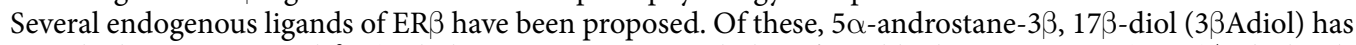
been studied most extensively ${ }^{3}$. $3 \beta$ Adiol is an estrogenic metabolite of $5 \alpha$-dihydrotestosterone (DHT) ${ }^{4}$. The binding affinity of $3 \beta$ Adiol is stronger for ER $\beta$ than for ER $\alpha^{5}$. In HT-22 neuronal cells, 33Adiol activates ER $\beta$-induced transcription mediated by an estrogen response element with the same efficacy as E2, and the transcriptional selectivity for $\mathrm{ER} \beta$ over $\mathrm{ER} \alpha$ is much greater than the binding selectivity in these neuronal cells ${ }^{6}$. Several animal experiment paradigms suggest that $3 \beta$ Adiol is anxiety reducing, cognitive enhancing ${ }^{7}$, and anti-depressive ${ }^{8}$ [reviewed in ${ }^{9}$ ]. Another endogenous ligand of ER $\beta$ is Androstenediol ( $\Delta 5$-diol), which is synthesized from dehydroepiandrosterone (DHEA) without the need for $5 \alpha$-reductase. The binding affinity of $\Delta 5$-diol is stronger for $\mathrm{ER} \beta$ than for $\mathrm{ER} \alpha$, and is similar to that of $3 \beta \mathrm{Adiol}^{5}$. $\Delta 5$-diol prevents activation of microglia ${ }^{10}$. DHEA is a precursor of both 33 Adiol and $\Delta 5$-diol (Fig. 1) ${ }^{11}$. Another ligand generated from DHEA by cytochrome P450, family 7 , subfamily B, polypeptide 1 (CYP7B1) is $7 \alpha$-hydroxy-dehydroepiandrosterone ( $7 \alpha-\mathrm{OH}$-DHEA), which

${ }^{1}$ Department of Psychiatry, Shinshu University School of Medicine, 3-1-1 Asahi, Matsumoto, Nagano 390-8621, Japan. ${ }^{2}$ Department of Psychiatry, National Hospital Organization Komoro Kogen Hospital, 4598 Ko, Komoro, Nagano 384-8540, Japan. ${ }^{3}$ ASKA Pharmaceutical Medical Co., Ltd. 5-36-1 Shimosakunobe, Kawasaki Takatsu-ku, Kanagawa 213-8522, Japan. Correspondence and requests for materials should be addressed to N.S. (email: nsugi@ shinshu-u.ac.jp) 


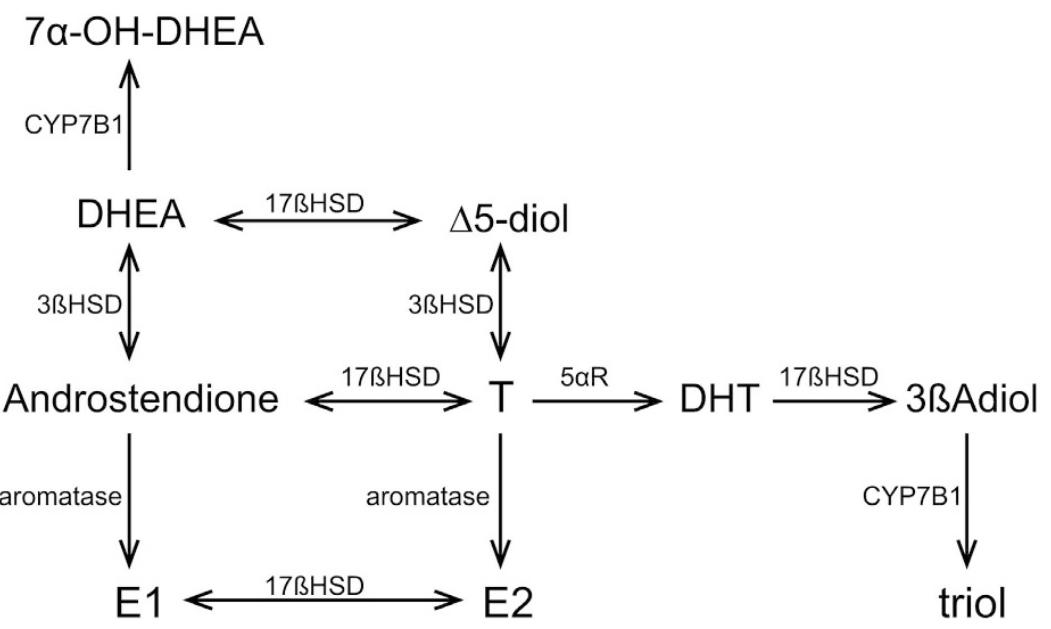

Figure 1. DHEA is a precursor of endogenous ligands for ER $\beta$. The main pathway of $3 \beta$ Adiol production is from testosterone (T). $\Delta^{4}$-3-ketosteroid- $5 \alpha$-reductase $(5 \alpha \mathrm{R})$ converts T to $5 \alpha$-dihydrotestosterone (DHT).

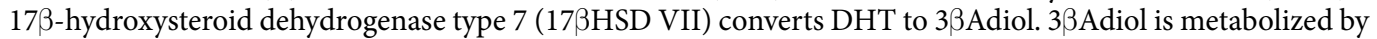
cytochrome P450, family 7 , subfamily B, polypeptide 1 (CYP7B1) to $5 \alpha$-androstane- $3 \beta, 7 \alpha, 17 \beta$-triol (triol). T is synthesized from $\Delta 5$-diol (Androstenediol) via $3 \beta \mathrm{HSD}$, and $\Delta 5$-diol is from DHEA (dehydroepiandrosterone) via $17 \beta$ HSD.

is an ER $\beta$ activator ${ }^{12,13}$. Although $7 \alpha-\mathrm{OH}-\mathrm{DHEA}$ is a less efficient $\mathrm{ER} \beta$ activator than $3 \beta \mathrm{Adiol}^{12,13}$, it is a candidate natural ligand for $\mathrm{ER} \beta$. In humans, the concentration of $7 \alpha-\mathrm{OH}-\mathrm{DHEA}$ in serum is strongly correlated with that in cerebrospinal fluid ${ }^{14}$. In this study, we investigated the pathway from DHEA to $3 \beta$ Adiol, $\Delta 5$-diol, and $7 \alpha-\mathrm{OH}-\mathrm{DHEA}$ in terms of the "DHEA-ER $\beta$ axis".

Depression is much more common in women than in men ${ }^{15,16}$ and the risk of depression increases during menopause ${ }^{17}$. The DHEA-ER $\beta$ axis may be involved in the etiophysiology of depression, especially in geriatric women.

We determined the serum and salivary levels of natural ER $\beta$ ligands in men and women with and without past depressive episodes. We focused on geriatric subjects close to the peak age of depression onset. In addition to an interview regarding menopause, we measured E2 levels in women. We measured cortisol (F) levels as a marker of general stress (For chemical structures of the steroids of interest, please see Supplementary Figure S1). We collected both saliva and serum to investigate the feasibility of estimating the serum levels of steroids without blood sampling. This preliminary study has generated the first data on the precise levels of endogenous ER $\beta$ ligands in geriatric subjects, as determined using liquid chromatography tandem mass spectrometry (LC-MS/ MS) technology.

\section{Results}

Clinical Data. The scores of psychiatric inventories confirmed the exclusion of subjects with an acute phase of depression, dementia, or mild cognitive impairment. No subject had a history of oophorectomy or orchidectomy. There was a significant difference in age of subjects between female controls and the female depression group $(\mathrm{p}<0.01$, Dunn's test). The homogeneity of variance was confirmed for BMI data $(\mathrm{p}=0.6999$, Bartlett's test), and there were no significant differences between the groups $(p=0.1609$, one-way ANOVA). There was no significant difference in body fat percentage or abdominal circumference between the control and depression groups of either sex (Welch's test). (Table 1).

Serum Levels of Steroids. There were no sex differences in the serum levels of DHEA and $7 \alpha-O H-D H E A$ either in control or depression subjects. However, there were statistically significant differences between sexes in the levels of 3 $\beta$ Adiol, $\Delta 5$-diol, and E2; males exhibited higher levels of these three steroids than females. The female control group had a higher level of DHEA than the female depression group. Because there was a significant difference in age between these two groups, Spearman correlation coefficients were used to evaluate the correlation between serum levels of DHEA and age; there were no significant correlations. The other steroids measured in this study did not differ between control and depression subjects. Male depression subjects had a higher level of $\mathrm{F}$ than female depression group (Table 2, Supplementary Figure S2).

Correlation between the Serum and Salivary Levels of Each Steroid. For DHEA, $7 \alpha-O H-D H E A$, and F, strong correlations were observed between serum and salivary levels. There were also correlations between serum and salivary levels of $3 \beta$ Adiol; however, most of the measured values of $3 \beta$ Adiol in saliva were under the quantitation limit. The measured values of $\Delta 5$-diol in both saliva and serum were within the quantitation limit, but there were no significant correlations between them. We failed to confirm a correlation between the levels of E2 in saliva and serum (Table 3, Supplementary Figure S3). 


\begin{tabular}{|c|c|c|c|c|c|c|}
\hline & $\begin{array}{c}\text { Male } \\
\text { controls } \\
(\mathrm{n}=12)\end{array}$ & $\begin{array}{l}\text { Female } \\
\text { controls } \\
(\mathrm{n}=16)\end{array}$ & $\begin{array}{c}\text { Male } \\
\text { depression } \\
(\mathrm{n}=10)\end{array}$ & $\begin{array}{c}\text { Female } \\
\text { depression } \\
(\mathrm{n}=13)\end{array}$ & Kruskal-Wallis test & Dunn's test \\
\hline Age & $65.7 \pm 5.7$ & $60.6 \pm 2.3$ & $67.4 \pm 7.0$ & $68.8 \pm 6.7$ & $\mathrm{H}=46.65, \mathrm{df}=3, \mathrm{p}=0.006$ & F/C vs. $F / D(p<0.01)$ \\
\hline Height $(\mathrm{cm})$ & $166.2 \pm 5.1$ & $155.9 \pm 4.7$ & $166.4 \pm 6.8$ & $152.3 \pm 4.6$ & & \\
\hline Weight (kg) & $70.3 \pm 9.5$ & $56.6 \pm 7.7$ & $66.9 \pm 7.0$ & $53.0 \pm 5.5$ & & \\
\hline BMI & $25.4 \pm 3.2$ & $23.3 \pm 3.1$ & $24.2 \pm 2.9$ & $22.9 \pm 2.3$ & $\mathrm{H}=46.62, \mathrm{df}=3, \mathrm{p}=0.193$ & \\
\hline Percentage of Body Fat (\%) & $24.3 \pm 4.3$ & $32.5 \pm 5.1$ & $24.0 \pm 3.7$ & $32.9 \pm 4.2$ & $\mathrm{H}=16.65, \mathrm{df}=3, \mathrm{p}<0.001$ & $\begin{array}{l}\text { M/C vs. F/C }(\mathrm{p}<0.01) \\
\mathrm{M} / \mathrm{C} \text { vs. F/D }(\mathrm{p}<0.01) \\
\text { F/C vs. } \mathrm{M} / \mathrm{D}(\mathrm{p}<0.01) \\
\mathrm{M} / \mathrm{D} \text { vs. } \mathrm{F} / \mathrm{D}(\mathrm{p}<0.01)\end{array}$ \\
\hline Abdominal Circumference $(\mathrm{cm})$ & $88.5 \pm 6.0$ & $82.2 \pm 10.0$ & $84.3 \pm 5.4$ & $78.3 \pm 7.3$ & $\mathrm{H}=46.62, \mathrm{df}=3, \mathrm{p}=4.18 \times 10^{-10}$ & $\mathrm{M} / \mathrm{C}$ vs. $\mathrm{F} / \mathrm{D}(\mathrm{p}<0.001)$ \\
\hline HAM-D17 & $2.0 \pm 2.1$ & $2.0 \pm 1.9$ & $4.6 \pm 2.3$ & $3.4 \pm 2.0$ & $\mathrm{H}=4.66, \mathrm{df}=3, \mathrm{p}=0.020$ & F/C vs. $\mathrm{M} / \mathrm{D}(\mathrm{p}<0.001)$ \\
\hline BDI-II & $4.1 \pm 2.4$ & $6.0 \pm 4.3$ & $6.0 \pm 4.1$ & $6.8 \pm 3.9$ & $\mathrm{H}=2.92, \mathrm{df}=3, \mathrm{p}=0.481$ & \\
\hline MMSE & $29.6 \pm 0.8$ & $29.7 \pm 0.5$ & $28.2 \pm 1.5$ & $28.1 \pm 1.9$ & $\mathrm{H}=3.89, \mathrm{df}=3, \mathrm{p}=0.274$ & \\
\hline FAB & $16.7 \pm 1.2$ & $17.1 \pm 0.7$ & $16.4 \pm 0.7$ & $15.9 \pm 1.5$ & $\mathrm{H}=6.73, \mathrm{df}=3, \mathrm{p}=0.094$ & \\
\hline CDR & 0 & 0 & 0 & 0 & & \\
\hline
\end{tabular}

Table 1. Clinical data for subjects. The values are shown as mean \pm standard deviation. Four group mean comparisons of anthropometric measurements and psychiatric inventories were performed. Abbreviations: BDI-II, Beck Depression Inventory II; $B M I$, Body Mass Index; CDR, Clinical Dementia Rating; FAB, Frontal Assessment Battery; HAM-D, Hamilton Rating Scale for Depression 17 items; MMSE, Mini Mental State Examination; F/C, female controls; $F / D$, female depression group; $M / C$, male controls; $M / D$, male depression group.

\section{Discussion}

It has been well established that the serum level of E2 is lower in women after menopause, and this may explain the high prevalence of depression in postmenopausal women. In contrast, elderly men do not have such an acute, dynamic change of endocrine system that occurs in women ${ }^{18-20}$. This could be one explanation of why depression is more common in women. Our data on serum E2 concentration agree well with other reports both in elderly men $^{21,22}$ and postmenopausal women ${ }^{23}$. The lower level of $\mathrm{E} 2$ in postmenopausal women than those in men might reflect that the production of E2 in women is highly dependent on ovarian function, whereas men produce E2 using the different pathway ${ }^{21,22}$.

In this study, we showed that not only levels of E2 were lower in women, both with and without depression, but levels of $3 \beta$ Adiol and $\Delta 5$-diol were also reduced. Interestingly, there was no sex difference in the level of DHEA, the precursor of these steroids. Levels of $7 \alpha-\mathrm{OH}-\mathrm{DHEA}$, a metabolite of DHEA with a weak affinity for $\operatorname{ER} \beta$, also did not differ between sexes. Both men and women with depression in this study were taking antidepressants as maintenance therapy, but showed the same trend in sex differences as in the control group. This suggests that sex difference is not a direct effect of antidepressant medication.

It is controversial whether hormone-replacement therapy (HRT) helps to keep women healthy after menopause. A large-scale randomized controlled study, the Women's Health Initiative (WHI), failed to show the benefit of $\mathrm{HRT}^{24}$. WHI sub-analysis by the age groups at which HRT was started suggests that HRT timing is important (timing hypothesis or critical window theory); if HRT is started early, it may decrease the risk of cardiovascular disease $^{25}$. Our previous animal model of postmenopausal depression also suggested a critical temporal window for hormone replacement ${ }^{1}$. However, the Kronos Early Estrogen Prevention Study (KEEPS), in which HRT was started within 3 years after menopause, revealed no difference between the treatment group and the placebo group in the annual change of carotid artery intima-media thickness. Here, we propose that not only E2, but also two other estrogenic steroids with an affinity for ER $\beta, 3 \beta$ Adiol and $\Delta 5$-diol, are important for HRT. According to the yin-yang hypothesis of ERs ${ }^{26}$, activation of $E R \alpha$ is anxiogenic and that of ER $\beta$ is anxiolytic and anti-depressive. This has been repeatedly confirmed by animal experiments ${ }^{26}$. In our model, LY3201 (an ER $\beta$-specific agonist) was more effective than E2 in maintaining high levels of TPH-positive neurons ${ }^{1}$. If an ER $\beta$-specific agonist is used for HRT within a critical temporal window instead of E2, HRT should result in decreased incidence and severity of postmenopausal depression. Negative data from the WHI and KEEPS suggest that timely E2 replacement is not enough. Because we are now aware of steroid metabolites that can selectively activate $E R \beta$, it is imperative that we investigate the role of these steroids in depression.

In order to rigorously test the relationship between $\operatorname{ER} \beta$ ligands and postmenopausal depression, we need to determine the levels of endogenous ER $\beta$ ligands in younger subjects and whether pre-menopausal women and men have similar ER $\beta$-ligand levels. Although they used a different measurement method with limitations, Habrioux et al. studied serum 3 3 Adiol levels of men and women aged 18 to 30 years ${ }^{27}$; the level in men was higher than that in women, but the sexual difference was smaller than that observed for the older individuals in our study.

In the present study, there were no differences between depressed patients and controls in the levels of $3 \beta$ Adiol or $\Delta 5$-diol. This was an unexpected result, as we assumed that normal healthy individuals without a history of depression had relatively high levels of these ER $\beta$ ligands. This might be because subjects in the depression group were fully remittent. If we were to collect samples during the acute phase of depression, differences in the levels of these ligands might be observed between groups. 


\begin{tabular}{|c|c|c|c|c|c|c|}
\hline & $\begin{array}{l}\text { Male Controls } \\
\quad(\mathrm{n}=12)\end{array}$ & $\begin{array}{l}\text { Female } \\
\text { Controls } \\
(\mathrm{n}=16)\end{array}$ & $\begin{array}{c}\text { Male } \\
\text { Depression } \\
(\mathrm{n}=10)\end{array}$ & $\begin{array}{c}\text { Female } \\
\text { Depression } \\
(\mathrm{n}=13)\end{array}$ & $\begin{array}{c}\text { Kruskal-Wallis } \\
\text { test }\end{array}$ & Dunn's test \\
\hline \multirow{2}{*}{$\mathrm{E} 2(\mathrm{pg} / \mathrm{mL})$} & \multirow{2}{*}{$15.87 \pm 5.56$} & \multirow{2}{*}{$2.24 \pm 1.39$} & \multirow{2}{*}{$21.23 \pm 8.20$} & \multirow{2}{*}{$2.08 \pm 1.36$} & \multirow{2}{*}{$\begin{array}{c}H=18.80 \\
d f=3 \\
p=1.87 \times 10^{-7}\end{array}$} & M/C vs. F/C $(\mathbf{p}<0.01)$ \\
\hline & & & & & & $\mathrm{M} / \mathrm{D}$ vs. $\mathrm{F} / \mathrm{D}(\mathrm{p}<0.001)$ \\
\hline DHEA (ng/mL) & $1.87 \pm 0.65$ & $2.24 \pm 0.83$ & $1.36 \pm 0.45$ & $1.50 \pm 1.29$ & $\begin{array}{c}H=9.18 \\
\mathrm{df}=3 \\
\mathrm{p}=0.003\end{array}$ & $\mathrm{~F} / \mathrm{C}$ vs. $\mathrm{F} / \mathrm{D}(\mathrm{p}<0.001)$ \\
\hline $7 \alpha-\mathrm{OH}-\mathrm{DHEA}(\mathrm{pg} / \mathrm{mL})$ & $147.92 \pm 67.59$ & $133.31 \pm 40.65$ & $113.06 \pm 54.28$ & $116.87 \pm 83.76$ & $\begin{array}{c}\mathrm{H}=2.81 \\
\mathrm{df}=3 \\
\mathrm{p}=0.203\end{array}$ & \\
\hline $3 \beta$ Adiol $(\mathrm{pg} / \mathrm{mL})$ & $25.08 \pm 20.06$ & $5.69 \pm 7.31$ & $22.23 \pm 10.22$ & $3.52 \pm 3.41$ & $\begin{array}{c}H=20.03 \\
d f=3 \\
p=1.11 \times 10^{-6}\end{array}$ & $\begin{array}{c}\text { M/C vs. F/C }(p<0.01) \\
\text { M/D vs. F/D }(p<0.001)\end{array}$ \\
\hline$\Delta 5$-diol (ng/mL) & $0.50 \pm 0.31$ & $0.23 \pm 0.07$ & $0.47 \pm 0.18$ & $0.16 \pm 0.13$ & $\begin{array}{c}H=19.15 \\
d f=3 \\
p=1.67 \times 10^{-5}\end{array}$ & $\begin{array}{l}\text { M/C vs. F/C }(\mathbf{p}<0.001) \\
\text { M/D vs. F/D }(\mathbf{p}<0.05)\end{array}$ \\
\hline $\mathrm{F}(\mathrm{ng} / \mathrm{mL})$ & $103.30 \pm 40.99$ & $82.22 \pm 26.87$ & $106.96 \pm 32.10$ & $72.08 \pm 19.59$ & $\begin{array}{c}\mathrm{H}=6.19 \\
\mathrm{df}=3 \\
\mathrm{p}=0.025\end{array}$ & M/D vs. F/D $(\mathbf{p}<0.05)$ \\
\hline
\end{tabular}

Table 2. Serum steroid levels. The values are shown as mean \pm standard deviation. Four group mean comparisons of serum levels of each steroid were performed. Abbreviations: $3 \beta$ Adiol, $5 \alpha$-androstane-

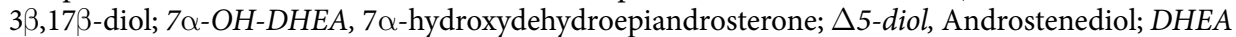
dehydroepiandrosterone; $E 2$, $17 \beta$-estradiol; $F$, cortisol; $F / C$, female controls; $F / D$, female depression group; $M / C$, male controls; $M / D$, male depression group.

\begin{tabular}{|l|c|c|c|c|c|}
\hline E2 & DHEA & 7 $\alpha$-OH-DHEA & 3 $\beta$ Adiol & $\boldsymbol{\Delta}$ 5-diol & F \\
\hline rs $=-0.274$ & $\mathrm{rs}=-0.564$ & $\mathrm{rs}=-0.546$ & $\mathrm{rs}=-0.351$ & $\mathrm{rs}=-0.267$ & $\mathrm{rs}=-0.438$ \\
\hline n.s. & $\mathrm{p}<0.001$ & $\mathrm{p}<0.001$ & $\mathrm{p}<0.05$ & n.s. & $\mathrm{p}<0.01$ \\
\hline
\end{tabular}

Table 3. Correlation between serum and salivary concentrations of each steroid. Spearman correlation coefficients were used to evaluate the correlation between the serum and the salivary concentrations of each steroid. Abbreviations: $3 \beta A d$ diol, $5 \alpha$-androstane-3 $\beta, 17 \beta$-diol; $7 \alpha-O H$-DHEA, $7 \alpha$-hydroxydehydroepiandrosterone; $\triangle 5$-diol, Androstenediol; DHEA, dehydroepiandrosterone; E2, 17 $\beta$-estradiol; F, cortisol.

As in earlier studies ${ }^{28,29}$, women in the present study with a history of depression had significantly lower levels of DHEA than control women. It remains difficult to connect lower levels of DHEA to the mechanism of postmenopausal depression. In this study, all depression subjects were fully remittent and exhibited no difference from controls in aspects of daily life. Moreover, although the average serum level of DHEA in female depression subjects was lower than that in controls, it was $1.50 \mathrm{ng} / \mathrm{mL}$. This is a very high concentration in comparison to other neuroactive steroids. Finally, there is no known specific controller of, or receptor for, DHEA. Therefore, we agree with recommendations of the Endocrine Society in 2014 that DHEA therapy should not be administered, because too many questions remain to justify its use ${ }^{30}$.

It seems unlikely that a lack of DHEA itself is responsible for depression in postmenopausal women. Instead, we assume that a high level of DHEA may indirectly reflect a strong DHEA-ER $\beta$ axis. Women with a strong DHEA-ER $\beta$ axis can generate $3 \beta$ Adiol and $\Delta 5$-diol from DHEA quickly, as needed to prevent acute phases of depression. An in vitro study suggested that high DHEA levels strongly suppress CYP7B1-mediated 33Adiol metabolism, resulting in high $3 \beta$ Adiol levels and increased ER $\beta$ activation ${ }^{13}$. To determine whether a strong DHEA-ER $\beta$ axis enables female patients to avoid depressive episode, a large-scale, population-based prospective cohort study measuring not only DHEA, but also $3 \beta$ Adiol and $\Delta 5$-diol, is needed. If we are correct, DHEA could be used as a reliable marker for vulnerability to postmenopausal depression.

Identifying the factors that control production of $3 \beta$ Adiol and $\Delta 5$-diol from DHEA is also of great importance in understanding the mechanism of estrogen-related depression. The duration of action of $3 \beta$ Adiol is determined by the concentration of CYP7B1 in the cells. This pathway from DHEA to effective levels of an ER $\beta$ ligand occurs within target cells and plasma levels of $3 \beta$ Adiol do not reflect what is occurring in the ER $\beta$ target cells. Much more effort is needed to understand how the component enzymes in this pathway are regulated and which of the steps are defective when, despite high levels of DHEA, insufficient $3 \beta$ Adiol is produced.

We must pay meticulous attention to minimize stress on subjects while collecting samples, especially from subjects with depression. In this study, we excluded patients in the acute phase of depression, and only recruited remittent patients in maintenance therapy. Rather than collect samples at multiple times throughout the day to check for circadian variation, we collected samples from all subjects at the same time of day. We also aimed to estimate the serum level of steroids using saliva without the need to draw blood. To collect blood or CSF, subjects must come to the hospital at a scheduled time and experience pain during collection. In contrast, saliva can be collected by subjects at home as many times as needed with minimal stress. In this study, we did not find 
convicting results showing correlation between salivary and serum levels of E2, 3ßAdiol, or $\Delta 5$-diol. However, we believe using saliva instead of blood is valuable for future projects and we hope to improve our methodology.

\section{Materials and Methods}

Study Subjects. This study was approved by the Ethics Committee of Shinhu University School of Medicine (No. 1839) and the National Hospital Organization of Komoro Kogen Hospital. Due to ethical issues regarding depression, we included only fully remitted patients in this study. This study was conducted in accordance with the principles of the Declaration of Helsinki. All participants provided written informed consent.

Between 2011 and 2014, a total of 51 subjects, $65.2 \pm 6.52$ years of age (mean \pm standard deviation), participated and were included in one of four groups: [1] nonclinical healthy geriatric males without any history of psychiatric or neurological disease (male control, $\mathrm{n}=12,65.7 \pm 6.01$ ); [2] female control ( $\mathrm{n}=16,60.6 \pm 2.42$ ); [3] male subjects with a diagnosis of major depressive disorder who were in full remission, meaning that they had at least one previous depressive episode, but were normal with medical care at the time of the study (male depression, $\mathrm{n}=10,67.4 \pm 7.38$ ); and [4] female depression $(n=13,68.8 \pm 6.95)$. Subjects in groups [3] and [4] were receiving outpatient care. All patients had been diagnosed by trained psychiatrists, and 18 of 23 were being treated with antidepressants at the time of the sampling ( 5 with paroxetine, 5 with sertraline, 4 with duloxetine, 2 with mirtazapine, 1 with escitalopram, and 1 with amitriptyline). Before enrollment in the study, one of the authors (M.K.), a trained psychiatrist, confirmed all diagnoses using the Diagnostic and Statistical Manual of Mental Disorders-IV-TR. The inclusion criteria were as follows: All participants were (a) aged over 55 and for women, they were after menopause, (b) able to give informed consent and (c) physically and endocrinologically healthy at the time of this study. For group [1] and [2]: (a), (b), (c), and (d) no history of psychiatric disorder in the past. For group [3] and [4]: (a), (b), (c) and (e) Diagnostic and Statistical Manual of Mental Disorder-IV-TR diagnosis of major depressive disorder, in full remission. Exclusion criteria are as follows: (a) severe general medical condition, (b) dementing illness or mild cognitive impairment, (c) other conditions that would affect the results of this study, such as daily use of estrogenic drugs or under the anti-estrogen therapy.

Clinical Data and Sample Collection. Anthropometric measurements (height, weight, body mass index [BMI], body fat percentage, abdominal circumference) and psychiatric inventories (17-item Hamilton Rating Scale for Depression [HAM-D], Beck Depression Inventory II [BeckII], Clinical Dementia Rating [CDR], Mini-Mental State Examination [MMSE], and Frontal Assessment Battery [FAB]) were conducted by a single trained psychiatrist (M.K.) at the time depression diagnoses were confirmed.

To avoid circadian variation of steroids levels, we collected samples from all subjects at the same time of day (10:00 a.m.). Blood was drawn while subjects were resting. Before collecting saliva, subjects rinsed their mouths with tap water. Separated serum and saliva were stored at $-20^{\circ} \mathrm{C}$ until they were processed for steroid measurement.

Steroid Measurement. Materials and Reagents. F, DHEA, $\Delta 5$-diol, E2, and fusaric acid (FA) were from Sigma-Aldrich (St. Louis, MO, USA). $7 \alpha-\mathrm{OH}-\mathrm{DHEA}$ and $3 \beta$ Adiol were from Steraloids (Newport, RI, USA). $\mathrm{F}_{-} \mathrm{d}_{4}$ was from $\mathrm{C} / \mathrm{D} / \mathrm{N}$ Isotopes Inc. (Quebec, Canada). DHEA- ${ }^{13} \mathrm{C}_{3}$ was synthesized at Tohoku Pharmaceutical University (Miyagi, Japan). $\Delta 5$-diol- $\mathrm{d}_{4}$ and $7 \alpha-\mathrm{OH}-\mathrm{DHEA}-\mathrm{d}_{2}$ were synthesized at ASKA Pharma Medical Co. Ltd. (Kanagawa, Japan). E2- ${ }^{13} \mathrm{C}_{4}$ was from Hayashi Pure Chemical Ind. Ltd. (Osaka, Japan). 4-dimethylaminopyridine (DMAP), 2-methyl-6-nitrobenzoic anhydride (MNBA), and picolinic acid (PA) were from Tokyo Chemical Industry (Tokyo, Japan). Triethylamine (TEA), O-ethylhydroxyl-ammonium chloride, pentafluoropyridine, and 1 $M$ sodium hydroxide solutions were from Wako Pure Chemical Industries (Osaka, Japan). OASIS MAX cartridge $(60 \mathrm{mg}, 3 \mathrm{~mL})$ was from Waters Corporation (Milford, MA, USA). InertSep SI cartridge (500 mg, $3 \mathrm{~mL}$ ) was from GL Science (Tokyo, Japan). All other reagents and solvents were of analytical grade.

Extraction and Purification. As internal standards, F- $\mathrm{d}_{4}$, DHEA- ${ }^{13} \mathrm{C}_{3}, \Delta 5-$ diol- $\mathrm{d}_{4}, 7 \alpha-\mathrm{OH}-\mathrm{DHEA}-\mathrm{d}_{2}$, and E2- ${ }^{13} \mathrm{C}_{4}$ were added to serum and saliva samples. Steroids were extracted with ethyl acetate. After the organic layer was evaporated to dryness, the extract was cleaned with an Oasis MAX cartridge. After purification, the extract was evaporated to dryness, and each steroid was then subjected to derivatization.

Derivatization and Application to LC-MS/MS. F, DHEA, $\Delta 5$-diol, and 33Adiol. The residue was treated with $50 \mu \mathrm{L}$ reagent mixture (MNBA, $80 \mathrm{mg}$; PA, $40 \mathrm{mg}$; DMAP, $20 \mathrm{mg}$ in $1 \mathrm{~mL}$ acetonitrile) and $10 \mu \mathrm{L}$ TEA, and then left at room temperature for $30 \mathrm{~min}$. After derivatization, the reaction mixture was purified with an InterSep SI cartridge. After purification, the extract was evaporated to dryness, the residue was dissolved in acetonitrile/ distilled water $(40: 60, \mathrm{v} / \mathrm{v})$, and the solution was subjected to LC-MS/MS. For quantitation, the $\mathrm{m} / z$ transitions $468.2 \rightarrow 309.2,472.2 \rightarrow 450.3$, 394.3 $\rightarrow 175.1,397.4 \rightarrow 178.4,501.3 \rightarrow 255.4,503.3 \rightarrow 257.1$, and $505.4 \rightarrow 259.3$ were selected for F, F- $\mathrm{d}_{4}$, DHEA, DHEA- ${ }^{13} \mathrm{C}_{3}, \Delta 5$-diol, $3 \beta$ Adiol, and $\Delta 5$-diol- $\mathrm{d}_{4}$, respectively.

$7 \alpha$-OH-DHEA. The residue was treated with $0.12 \mathrm{~mL}$ reaction mixture $(20 \mathrm{mg} O$-ethylhydroxyl-ammonium chloride in $1 \mathrm{~mL}$ acetonitrile/distilled water $(60: 40, \mathrm{v} / \mathrm{v})$ ) for $30 \mathrm{~min}$ at $60^{\circ} \mathrm{C}$. After derivatization, the reaction mixture was subjected to LC-MS/MS. For quantitation, the $\mathrm{m} / z$ transitions $348.2 \rightarrow 270.0$ and $351.1 \rightarrow 273.2$ were selected for $7 \alpha-\mathrm{OH}-\mathrm{DHEA}$ and $7 \alpha-\mathrm{OH}-\mathrm{DHEA}-\mathrm{d}_{2}$, respectively.

E2. The residue was reacted with the reaction mixture $(50 \mu \mathrm{L}$ pentafluoropyridine, $40 \mu \mathrm{L} 1 \mathrm{M}$ sodium hydroxide solution, $100 \mu \mathrm{L}$ acetonitrile, and $20 \mu \mathrm{L}$ ethanol) for $20 \mathrm{~min}$ at room temperature. After the reaction, the mixture was evaporated to dryness. Distilled water was added to the residue, and derivatized E2 was extracted with hexane. After the hexane layer was evaporated to dryness, the extracted E2 underwent further derivatization. The 
residue was reacted with $50 \mu \mathrm{L}$ of reagent mixture (MNBA, $80 \mathrm{mg}$; FA, $40 \mathrm{mg}$; DMAP, $20 \mathrm{mg}$ in $1 \mathrm{~mL}$ acetonitrile) and $10 \mu \mathrm{L}$ TEA, and then left at room temperature for $30 \mathrm{~min}$. After derivatization, the reaction mixture was cleaned with an InterSep SI cartridge. After purification, the extract was evaporated to dryness, the residue was dissolved in acetonitrile/distilled water $(80: 20, \mathrm{v} / \mathrm{v})$, and the solution was subjected to LC-MS/MS. For quantitation, the $m / z$ transitions $583.3 \rightarrow 308.1$ and $587.2 \rightarrow 311.8$ were selected for E2 and E2- ${ }^{13} \mathrm{C}_{4}$, respectively.

Data Analysis and Statistics. Analyses were performed using StatMate IV for Windows (ATOMS, Tokyo, Japan). All statistical tests were two-sided, and significance was defined as $\mathrm{p}<0.05$. Based on the preliminary nature of the study, calculation of sample size based on specific hypotheses was not appropriate.

Group mean comparisons of the serum and salivary levels of each steroid were performed using KruskalWallis $\mathrm{H}$ statistics and chi-square distributions. If Kruskal-Wallis $\mathrm{H}$ tests were significant, differences between pairs of groups were evaluated by multiple comparisons using Dunn's tests. Spearman correlation coefficients were used to evaluate the correlation between the serum and salivary levels of each steroid. Missing data were excluded from analyses.

BMI was compared between groups using one-way analysis of variance (ANOVA) after homogeneity of variance was assessed by Bartlett's test. Mean body fat percentages and abdominal circumferences of control and depression groups of each sex were compared using variance ratio $\mathrm{F}$ and Welch's tests after homogeneity of variance was assessed using $\mathrm{F}$ tests.

Some values of E2, $7 \alpha-\mathrm{OH}$-DHEA, $\Delta 5$-diol, and $3 \beta$ Adiol were under the limit of quantitation. The lower lim-


pg/assay; and F, 50 pg/assay.

\section{References}

1. Suzuki, H. et al. Involvement of estrogen receptor beta in maintenance of serotonergic neurons of the dorsal raphe. Mol Psychiatry 18, 674-680 (2013)

2. Donner, N. \& Handa, R. J. Estrogen receptor beta regulates the expression of tryptophan-hydroxylase 2 mRNA within serotonergic neurons of the rat dorsal raphe nuclei. Neuroscience 163, 705-718 (2009).

3. Sugiyama, N. et al. Spatiotemporal dynamics of the expression of estrogen receptors in the postnatal mouse brain. Mol Psychiatry 14, 223-232, 117 (2009).

4. Eckstein, B. \& Ravid, R. On the mechanism of the onset of puberty: identification and pattern of 5 alpha-androstane- 3 beta, 17 betadiol and its 3 alpha epimer in peripheral blood of immature female rats. Endocrinology 94, 224-229 (1974).

5. Kuiper, G. G. et al. Comparison of the ligand binding specificity and transcript tissue distribution of estrogen receptors alpha and beta. Endocrinology 138, 863-870 (1997).

6. Pak, T. R. et al. The androgen metabolite, 5alpha-androstane-3beta, 17beta-diol, is a potent modulator of estrogen receptor-beta1mediated gene transcription in neuronal cells. Endocrinology 146, 147-155 (2005).

7. Frye, C. A., Koonce, C. J., Edinger, K. L., Osborne, D. M. \& Walf, A. A. Androgens with activity at estrogen receptor beta have anxiolytic and cognitive-enhancing effects in male rats and mice. Horm Behav 54, 726-734 (2008).

8. Huang, Q., Zhu, H., Fischer, D. F. \& Zhou, J. N. An estrogenic effect of 5alpha-androstane-3beta, 17beta-diol on the behavioral response to stress and on CRH regulation. Neuropharmacology 54, 1233-1238 (2008).

9. Handa, R. J., Pak, T. R., Kudwa, A. E., Lund, T. D. \& Hinds, L. An alternate pathway for androgen regulation of brain function: activation of estrogen receptor beta by the metabolite of dihydrotestosterone, 5alpha-androstane-3beta,17beta-diol. Horm Behav 53, 741-752 (2008).

10. Saijo, K., Collier, J. G., Li, A. C., Katzenellenbogen, J. A. \& Glass, C. K. An ADIOL-ERbeta-CtBP transrepression pathway negatively regulates microglia-mediated inflammation. Cell 145, 584-595 (2011).

11. Warner, M. \& Gustafsson, J. A. DHEA - a precursor of ERbeta ligands. J Steroid Biochem Mol Biol 145, 245-247 (2015).

12. Martin, C. et al. CYP7B generates a selective estrogen receptor beta agonist in human prostate. J Clin Endocrinol Metab 89, 2928-2935 (2004).

13. Pettersson, H., Holmberg, L., Axelson, M. \& Norlin, M. CYP7B1-mediated metabolism of dehydroepiandrosterone and 5alphaandrostane-3beta,17beta-diol--potential role(s) for estrogen signaling. FEBS J 275, 1778-1789 (2008).

14. Kancheva, R. et al. Peripheral neuroactive steroids may be as good as the steroids in the cerebrospinal fluid for the diagnostics of CNS disturbances. J Steroid Biochem Mol Biol 119, 35-44 (2010).

15. Weissman, M. M. et al. Sex differences in rates of depression: cross-national perspectives. J Affect Disord 29, 77-84 (1993).

16. Kessler, R. C. et al. The epidemiology of major depressive disorder: results from the National Comorbidity Survey Replication (NCS-R). JAMA 289, 3095-3105 (2003).

17. Freeman, E. W. et al. Hormones and menopausal status as predictors of depression in women in transition to menopause. Arch Gen Psychiatry 61, 62-70 (2004)

18. Nyante, S. J. et al. Trends in sex hormone concentrations in US males: 1988-1991 to 1999-2004. Int J Androl 35, 456-466 (2012).

19. Taya, M. et al. Comparison of testosterone fractions between Framingham Heart Study participants and Japanese participants. Int $J$ Urol 21, 689-695 (2014).

20. Kelsey, T. W. et al. A validated age-related normative model for male total testosterone shows increasing variance but no decline after age 40 years. Plos One 9 , e109346 (2014).

21. Faqehi, A. M. et al. Derivatization of estrogens enhances specificity and sensitivity of analysis of human plasma and serum by liquid chromatography tandem mass spectrometry. Talanta 151, 148-156 (2016).

22. Wang, Q. et al. Ultrasensitive quantification of serum estrogens in postmenopausal women and older men by liquid chromatographytandem mass spectrometry. Steroids 96, 140-152 (2015).

23. Kinoshita, T. et al. An innovative LC-MS/MS-based method for determining CYP 17 and CYP 19 activity in the adipose tissue of pre- and postmenopausal and ovariectomized women using 13C-labeled steroid substrates. J Clin Endocrinol Metab 99, 1339-1347 (2014).

24. Rossouw, J. E. et al. Risks and benefits of estrogen plus progestin in healthy postmenopausal women: principal results From the Women's Health Initiative randomized controlled trial. JAMA 288, 321-333 (2002).

25. Hsia, J. et al. Conjugated equine estrogens and coronary heart disease: the Women's Health Initiative. Arch Intern Med 166, 357-365 (2006).

26. Sugiyama, N., Barros, R. P., Warner, M. \& Gustafsson, J. A. ERbeta: recent understanding of estrogen signaling. Trends Endocrinol Metab 21, 545-552 (2010).

27. Habrioux, G., Desfosses, B., Condom, R., Faure, B. \& Jayle, M. Simultaneous radioimmunoassay of 5alpha-androstane-3alpha, 17beta-diol and 5alpha-androstane-3beta, 17beta-diol unconjugated and conjugated in human serum. Steroids 32, 61-71 (1978). 
28. Barrett-Connor, E., von Muhlen, D., Laughlin, G. A. \& Kripke, A. Endogenous levels of dehydroepiandrosterone sulfate, but not other sex hormones, are associated with depressed mood in older women: the Rancho Bernardo Study. J Am Geriatr Soc 47, 685-691 (1999).

29. Morgan, M. L. et al. Neuroactive steroids after estrogen exposure in depressed postmenopausal women treated with sertraline and asymptomatic postmenopausal women. Arch Womens Ment Health 13,91-98 (2010).

30. Wierman, M. E. et al. Androgen therapy in women: a reappraisal: an Endocrine Society clinical practice guideline. J Clin Endocrinol Metab 99, 3489-3510 (2014).

\section{Acknowledgements}

We thank our colleagues, Yoshihiro KINOSHITA, Mitsuhiro MIYASHITA, Tetsuya HAGIWARA, Hisashi KITO, Toshinori NAKAMURA, Takehiko YASAKI, Yuka TAKAHASHI, Tomomi OGIHARA, Shin INUZUKA, and Tohru TAKAHASHI of the Department of Psychiatry, Shinshu University School of Medicine, and Eriko SASAKI, Tomonori FUKE, Yoshie MIYAIRI, and Hitoshi KITA of the Department of Psychiatry, National Hospital Organization, Komoro Kogen Hospital for their support for recruitment of the study participants. This research was supported by Japan Society for the Promotion of Science (Grant-in-Aid for Young Scientists (B) 24791209 to NS).

\section{Author Contributions}

M.K., N.S., D.S., K.A. and S.W. designed the study. M.K. engaged in clinical data collection, psychiatric assessments and sample (blood and saliva) collection. M.K., N.S. and K.A. engaged in clinical assessments and recruitment of subjects. H.S. and Y.M. measured the serum and salivary levels of steroids. M.K., N.S., D.S. and S.W. analyzed the data, discussed the results and wrote the paper.

\section{Additional Information}

Supplementary information accompanies this paper at http://www.nature.com/srep

Competing financial interests: The authors declare no competing financial interests.

How to cite this article: Kobayashi, M. et al. Sex differences in the serum level of endogenous ligands for estrogen receptor $\beta$ in the elderly population. Sci. Rep. 6, 25878; doi: 10.1038/srep25878 (2016).

(c) (i) This work is licensed under a Creative Commons Attribution 4.0 International License. The images or other third party material in this article are included in the article's Creative Commons license, unless indicated otherwise in the credit line; if the material is not included under the Creative Commons license, users will need to obtain permission from the license holder to reproduce the material. To view a copy of this license, visit http://creativecommons.org/licenses/by/4.0/ 